\title{
The 357 Data Collection System for Circulation Control
}

\begin{abstract}
Installation of an IBM 357 Data Collection System in circulation control appears warranted when: (1) shared time is available on a computer; (2) most circulation is done from one point; and (3) more than $\$ 2,500$ is being spent annually on filing, card pulling, and preparation of overdue notices. Questionnaires were sent to sixty medium-sized college and university libraries to determine how many institutions meet these prerequisites. Forty-two of forty-seven respondents have access to computers, twenty-three do all of their circulating of books from a single point, and thirty are spending more than $\$ 2,500$ annually on circulation record-keeping. Thus, a majority of the libraries polled could feasibly make use of the system.
\end{abstract}

$I_{1}$ N THE PAST YEAR an automated circulation system that seems to show great promise has been developed. This system has not been fully proven, but it does appear to be one of the best methods yet devised for handling automatically the laborious and time-consuming tasks involved in circulation work.

Many had an opportunity to observe the IBM 357 Data Collection System in action at the St. Louis Conference; the 357 , a key punch, and their components are all that are required for each circulation point in the library. This equipment rents from $\$ 2,500$ to $\$ 3,000$ annually, depending on the locality. Most libraries find it hard to hire one clerk for this sum.

This low price is somewhat deceptive, however, for we also need the equipment to process the circulation cards

Mr. Harris is Social Science Reference Librarian in Florida Atlantic University, Boca Raton. created by the 357 Data Collection System. An IBM 1401 computer works nicely, and here lies the difficulty. ${ }^{1}$ No library is willing to invest several hundred thousand dollars in a computer simply to provide automated circulation control.

One solution to this problem is for the library to make use of free or inexpensive time available at school computer facilities. But even if a library has access to such facilities this system would still be impractical unless most of the circulation is done from one point, and over $\$ 2,500$ a year is spent for the filing and pulling of charge cards and the preparation of overdues.

Several months ago a questionnaire was prepared in an attempt to ascertain whether or not there were libraries on medium-sized college and university campuses in this country which could

\footnotetext{
1 There are other methods: see Donald Kraft, $A$ Total Systems Approach to Library Mechanization (Chicago: IBM, 1964). Processed.
} 
meet these prerequisites. It was sent to colleges and universities in forty-nine states. The schools chosen had an average enrollment of sixty-five hundred.

Sixty questionnaires were sent out, and forty-seven were returned. The questionnaire set out to ascertain three major points:

1. The first was whether or not the libraries surveyed had access to one or more hours of computer time in each twenty-four hour period. ${ }^{2}$ Forty-two libraries indicated that their schools housed computers that could be used by the library. Thirty-eight of the forty-two indicated that the computer facilities were produced by IBM. Twenty-two of the forty-two schools owned their computers while the others rented them: eleven on a twenty-four hour basis; three on a monthly basis; and six on an eight-hour per day basis.

2 . The second concern was with the number of circulation points. Twentythree of the libraries did all of their circulation from one point while ten had only two circulation points. The greatest number reported was six.

3 . The last point dealt with was circulation costs. Thirty libraries reported that they were spending over $\$ 2,500$ a year on the filing and pulling of circulation cards and the preparing of overdues. $^{3}$

The practical, functional aspects of automated circulation control have long been accepted. Most librarians would welcome a circulation system that enables them to keep accurate statistics, prepares multiple copies of the daily circulation lists, and at the same time cuts the need for the filing and pulling of cards and the manual preparation of overdues.

The cry has usually been that we "Just can't justify the cost." The purpose of this study was to point out that for many

\footnotetext{
${ }^{2}$ After 10:00 P.M. would be a good time to process these cards.

${ }^{3}$ Figuring at $\$ 1.00$ an hour.
}

libraries across the land a 357-system offers both economy and efficiency, for many libraries are already spending what it would cost to rent the equipment. Critics of the system will be quick to remind that this price covers only the library equipment, and not the cost of the computer time.

The questionnaire shows, however, that twenty-two libraries indicated that their schools owned computers and that time was available for library use. At the same time eleven others indicated that the computers on their campuses were rented on a twenty-four hour basis with some free time for library use. In other words, thirty-three of the fortytwo libraries returning the questionnaire had access to "free" computer time. ${ }^{4}$

The results indicate that the majority of the libraries surveyed could feasibly make use of the new circulation system. The high rate of return of this questionnaire also seems to show a great deal of interest on the part of librarians in a better form of circulation control.

This system is especially tempting for those librarians who would like to automate just this one phase of their service, without being forced by the expense of the equipment to plan for total automation of the library. There are, of course, some expenses involved in the changeover which must be considered. Two such expenses would be the need for a punched card for each book in the collection, ${ }^{5}$ and a plastic ID card for each user.

In short, this system offers possibilities for certain libraries to improve eco-

(Continued on page 158)

\footnotetext{
4 The cost of personnel to process the cards and the machine expenses (other than rent which is already being paid on the time whether it is in use or not) will usually fall on the computer center.

5 Trueswell says, "It is not necessary and perhaps relatively more costly to prepare punched book cards for all books in the collection." It would be better to punch cards as the books are checked out. Richard W. Trueswell, "Two Characteristies of Circulation and Their Effects on the Implementation of Mechanized Circulation Control Systems," CRL, XXV (July 1964), 291.
} 
point is that if the lower schools ever do put into practice some of the new ideas, the graduates of these schools will come to college with learning equipment that will force us to raise our library sights many notches."

Beyond listing the libraries whose building plans are presented and discussed in Section Two little more need be said about this publication. For the most part the plans speak for themselves more eloquently than do the critics. They would speak even more clearly if dimensions were consistently given or, at the very least, a scale were provided for each plan. In addition to four public and six school libraries, the lineup of college buildings is as follows: University of Pittsburgh library; Alma College library, Alma, Mich.; University of Alberta library; John Carroll University library, University
Heights, Ohio; Newark Colleges of Rutgers University library; and Oregon State University library, Corvallis.-John P. McDonald, University of Connecticut.

\section{COLLECTION SYSTEM}

(Continued from page 120)

nomically, as well as efficiently, their circulation services. Because of the lack of the need for elaborate systems engineering and the relatively low cost of the library-based equipment, this is a system worthy of a closer look from those libraries which have access to a computer, are spending $\$ 2,500$ or more on circulation procedures, and which have a minimum number of circulation points.

\section{Preconference Library Buildings Institute}

The Library Administration Division Preconference Library Buildings Institute is scheduled for July 1-3 and will be held at the Sheraton-Cadillac Hotel, Detroit, Michigan. The registration fee of $\$ 12.00$ should be sent to the LAD office at ALA headquarters.

The institute will consist of an opening general session, which will be devoted to a discussion of mistakes that have been made in recent library buildings, and five meetings for each of the three types of libraries-public libraries, school libraries, and college and university libraries.

The LAD Architecture Committee for Public Libraries, in cooperation with the American Library Trustees Association, will devote two of its meetings to the role of the trustee in library planning and two other meetings to the presentation and critiques of public library plans. The Resources and Technical Services Division will cooperate in the presentation of a final session which will consider the planning of a technical processing area in a large public library.

The Buildings Committee for College and University Libraries will devote four of its meetings to the presentation and critiques of plans of junior college, college, and university libraries. The final session will be devoted to the planning of a technical processing area in a large university library.

"The Planning School Library Quarters Committee is arranging sessions on "Team Planning the School Library"; "Planning a Central Office Processing Center"; "Novel and Ingenious School Libraries"; and "Accommodating Non-print Materials and Equipment in School Library Quarters." Their last session will consist of a tour to a selected number of school libraries in the Detroit area. 